\title{
Supervised machine learning
}

\author{
based models predicting soil
}

\author{
surface area among different
}

\author{
taxonomical soil "types" using
}

\section{water adsorption curves}

Mark Chappell*1, Christian McGrath, Joshua LeMonte,

Matthew Middleton, Christine Miller, Renee Styles,

Cynthia Price, and Lesley Miller

${ }^{1}$ U.S. Army Engineer Research \& Development Center,

Vicksburg, MS USA; mark.a.chappell@usace.army.mil

This paper discusses a new Pedo-Informatic (P-I) paradigm, where complex soil behaviour of different soil "types" is predicted using machine learning (ML) based models. Here, we discuss ongoing work to develop P-I models that predict the surface area of soils. For this work, collected field soils were physically and chemically characterized to build multivariate signatures from the decomposition of centered log-ratio "compositions" using the nonlinear dimension reduction technique, UMAP. These compositions predicted the assigned NRCS designations with 95-100\% accuracy. Ongoing work correlating surface area of different soil "types" using supervised regression techniques will be discussed. The results are expected to generate a framework by which functional soil surface areas can be predicted based on NRCS soil taxonomic designations. 
This abstract is too long to be accepted for publication.

Please revise it so that it fits into the column on one page. 